\title{
ADUBAÇÃO POTÁSSICA E SEU EFEITO RESIDUAL NO SISTEMA SOJA-MILHO SAFRINHA EM MATO GROSSO
}

\author{
ANDERSON LANGE ${ }^{1}$, EDILSON CAVALLI $^{2}$, CASSIANO CAVALLI $^{2}$ \\ e ANTONIO CARLOS BUCHELT ${ }^{3}$
}

\author{
${ }^{1}$ Universidade Federal de Mato Grosso, Campus de Sinop. \\ Rua Alexandre Ferronato, 1200. Distrito Industrial. CEP 78550-000; Sinop-MT. paranalange@hotmail.com \\ ${ }^{2}$ Instituto Agronômico Campinas-IAC. Avenida Barão de Itapura, 1.481. Bairro Bota Fogo. CEP 13020-902; Campinas-SP. \\ edilso_c@hotmail.com,cavallicassiano@gmail.com, \\ ${ }^{3}$ Universidade do Estado de Mato Grosso, Campus Alta Floresta. \\ Av. Perimetral Deputado Rogério Silva - Norte 2, Alta Floresta - MT, CEP-78580-000. antoniobuchelt@hotmail.com
}

Revista Brasileira de Milho e Sorgo, v.18, n.2, p. 192-205, 2019

\begin{abstract}
RESUMO - O Estado de Mato Grosso se destaca no cenário nacional no que diz respeito à produção agrícola, mesmo assim pesquisas sobre adubações específicas para a região ainda são incipientes. Assim, objetivou-se com esse trabalho avaliar o desempenho agronômico e os teores de nutrientes no solo e na planta, no sistema soja-milho safrinha, em função de doses de potássio aplicadas no milho safrinha. O estudo foi realizado na região Médio Norte do estado, com doses de potássio $\left(0,40,80\right.$ e $120 \mathrm{~kg} \mathrm{ha}^{-1}$ de $\left.\mathrm{K}_{2} \mathrm{O}\right)$ na cultura do milho safrinha, sendo avaliado o efeito residual nas safras subsequentes (soja e milho safrinha). Foram avaliadas as alterações químicas no solo, as concentrações de nutrientes na folha, sua extração e exportação, bem como os parâmetros agronômicos nos três cultivos. A soja em solo com teor adequado de $\mathrm{K}$ foi pouca responsiva à adubação potássica, no sistema soja-milho safrinha, porque as reservas no solo e nos restos culturais do milho safrinha supriram suas necessidades. As doses de K afetaram a concentração de $\mathrm{Mg}$ nos tecidos foliares da soja e de N, K, Ca e Mg no milho, interferindo na taxa de extração e exportação de nutrientes no sistema soja-milho safrinha. O K apresenta movimentação no perfil, mesmo em solo argiloso sob baixa precipitação. Palavras-chave: exportação, extração, manejo da adubação, Zea mays, Glicine max.
\end{abstract}

\section{POTASSIUM FERTILIZATION AND ITS RESIDUAL EFFECT ON THE SOYBEAN-CORN SYSTEM IN MATO GROSSO STATE-BRAZIL}

\begin{abstract}
The state of Mato Grosso stands out in the national scenario with regard to agricultural production, although research on specific fertilizers for the region is still incipient. Thus, the objective of this work was to evaluate the agronomic performance and nutrient content in soil and plant in the soybean-corn system as a function of potassium rates. The study was carried out in the northern region of the state, with potassium rates $\left(0,40,80\right.$ and $120 \mathrm{~kg}^{-1}$ $\mathrm{K}_{2} \mathrm{O}$ ) in the second crop corn, and the residual effect was evaluated in the subsequent crops (soybean and second crop corn). The chemical changes in the soil, the nutrient concentrations in the leaf, its extraction and export, as well as the agronomic parameters in the three crops were evaluated. The soybean grown in soil with adequate K content was little responsive to potassium fertilization in the soybean-corn second crop system, because the reserves in the soil and in the crop remains of the corn second crop supplied their needs. The $\mathrm{K}$ rates affected the concentration of $\mathrm{Mg}$ in soybean foliar tissues and $\mathrm{N}, \mathrm{K}, \mathrm{Ca}$ and $\mathrm{Mg}$ in corn, interfering in the rate of extraction and export of nutrients in the soybean/ corn second crop system. The K presented movement in the profile, even in clay soil under low precipitation.
\end{abstract}

Keywords: export, extraction, fertilization management, Zea mays, Glicine max. 
Em regiões em que há possibilidade do cultivo de duas safras no mesmo ano agrícola, o sistema de cultivo sucessão soja-milho safrinha é amplamente praticado. O Estado de Mato Grosso (MT) prática largamente este sistema de cultivo, ocupando lugar de destaque no cenário agrícola nacional e mundial, produzindo 30\% da soja e 25\% do milho no País (Conab, 2016). Mesmo o estado sendo um dos maiores produtores dessas culturas, ainda se tem pouca pesquisa, sendo os dados utilizados provenientes de pesquisas de outras regiões, o que pode restringir as respostas à adubação. Para Petter et al. (2012), as recomendações de fertilizantes potássicos não devem ser extrapoladas de uma região para outra, mesmo que estas sejam do mesmo bioma.

Há pouco tempo, as respostas à adubação na cultura do milho ficavam mais restritas a Nitrogênio (N) e Fósforo (P) (Coelho et al., 2007). Respostas à adubação potássica não eram muito expressivas em razão da baixa produtividade e do cultivo em áreas com razoável teor de $\mathrm{K}$, nas frações trocável e não trocável do solo (Takasu et al., 2014). Nos últimos anos, com o aumento da produtividade, é possível detectar respostas à adubação potássica em solos de baixa fertilidade e com doses de até $120 \mathrm{~kg} \mathrm{ha}^{-1}$ de $\mathrm{K}_{2} \mathrm{O}$ para o milho (Coelho, 2006).

A evolução na produtividade do milho safrinha no estado é crescente nos últimos 20 anos, passando de aproximadamente 2.400 para $6.000 \mathrm{~kg} \mathrm{ha}^{-1}$ (Conab, 2016). Este aumento de $150 \%$ na produtividade muda completamente a dinâmica da adubação. Somase a este fato a maior precocidade dos materiais utilizados, tornando-os mais suscetíveis a deficiências nutricionais.

As respostas à adubação potássica da soja são menos expressivas, geralmente condicionadas a teores no solo muito baixos (Scherer, 1998), isto por cau- sa da sua menor exigência. Diferentemente do milho, a produtividade da soja no estado está praticamente estável nos últimos 20 anos, mantendo-se próxima a $3.000 \mathrm{~kg} \mathrm{ha}^{-1}$ (Conab, 2016).

O K é o segundo elemento mais absorvido pelas plantas, e sua reserva mineral nos solos da região Médio Norte de Mato Grosso é muito pequena, insuficiente para suprir a necessidade das culturas em cultivos sucessivos (Petter et al., 2012). Por outro lado, adubações com $\mathrm{K}$ em áreas com teor adequado do nutriente no solo não refletem em ganhos na produtividade, e pode haver perdas por lixiviação, potencializadas em solos de textura média a arenosa, baixa capacidade de troca de cátions (CTC) potencial e/ou efetiva e, principalmente, alta pluviosidade anual, condições encontradas na região.

Nesse contexto, objetivou-se avaliar o desempenho agronômico e os teores de nutrientes no solo e na planta, no sistema soja-milho safrinha, em função de doses de potássio aplicadas no milho safrinha.

\section{Material e Métodos}

O estudo foi conduzido no município de Sorriso-MT ( $\mathrm{S}=12^{\circ} 31^{\prime} 06^{\prime}$ "; $\mathrm{W}=55^{\circ} 40^{\prime} 22^{\prime \prime}$ e altitude de $365 \mathrm{~m}$ ), de março de 2014 a junho de 2015. As variações climáticas ocorridas no decorrer do desenvolvimento dos experimentos estão dispostas na Figura 1.

O clima da região é classificado como Aw, tropical quente, segundo classificação de Köppen, possui duas estações do ano bem definidas, sendo elas o verão chuvoso e o inverno seco. A amostragem inicial de solo foi realizada previamente à implantação do experimento. A área escolhida possuía teor de $\mathrm{K}$ no solo acima da faixa considerado adequada (Vilela et al., 2004; Alvarez V. et al., 1999), para se testar a res- 
posta das culturas a adubação potássica em solos com altos teores de K. O solo é classificado como Latossolo Vermelho-Amarelo, sendo as suas características físico-químicas apresentadas na Tabela 1.

O experimento foi implantado no período denominado safrinha, no dia 5 de março de 2014, de forma simultânea foi realizada a semeadura, aduba- ção do milho e a aplicação dos tratamentos, que nesta ocasião foram quatro doses de $\mathrm{K}_{2} \mathrm{O}(0,40,80$ e 120 $\mathrm{kg} \mathrm{ha}^{-1}$ ) na forma de $\mathrm{KCl}$, aplicadas a lanço em superfície, num delineamento de blocos casualizados, com seis repetições. As parcelas experimentais apresentavam dimensões de $6,60 \times 6,00 \mathrm{~m}$, totalizando 12 linhas espaçadas $0,55 \mathrm{~m}$ entre si. A área útil da par-

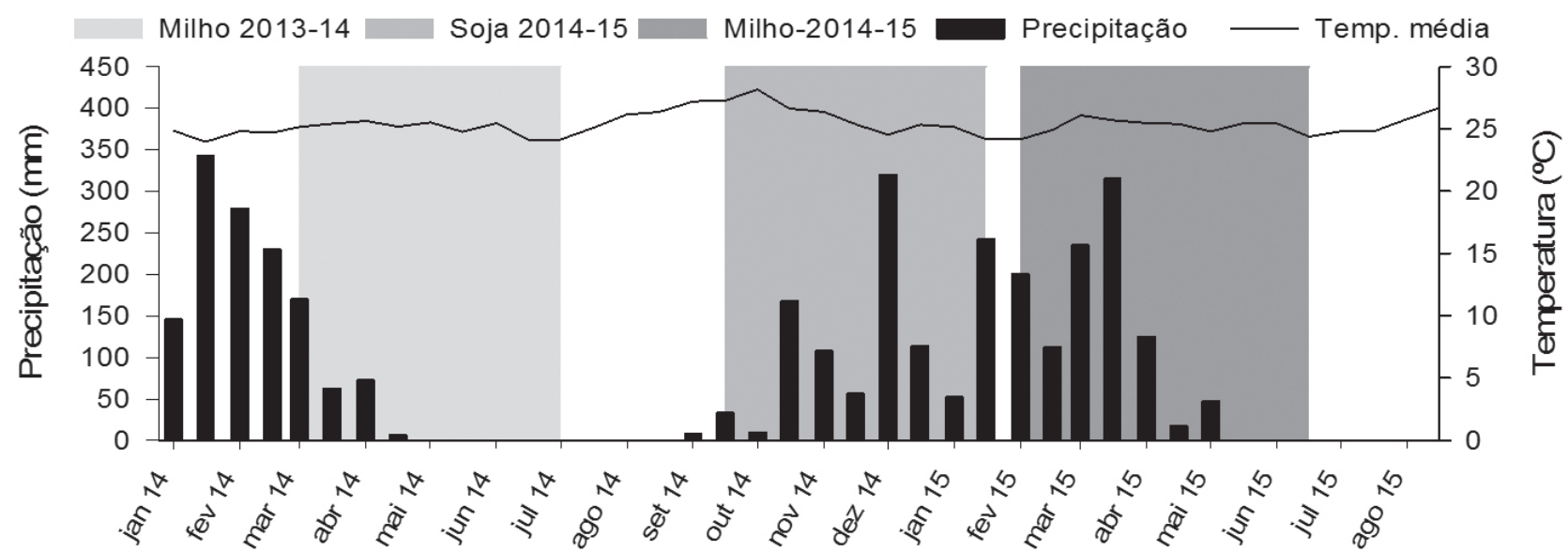

Figura 1. Precipitação acumulada e temperatura média, para o município de Sorriso-MT, de janeiro de 2014 a agosto de 2015 (fonte: Fundação Mato Grosso).

Tabela 1. Caracterização inicial do solo utilizado no experimento, em Sorriso-MT, no ano de 2013.

\begin{tabular}{|c|c|c|c|c|c|c|c|c|c|}
\hline \multirow[t]{3}{*}{ Camadas (m) } & \multicolumn{9}{|c|}{ Química $^{1}$} \\
\hline & $\mathrm{pH}$ & M.O & $\mathrm{P}$ & $\mathrm{K}$ & $\mathrm{Ca}$ & $\mathrm{Mg}$ & $\mathrm{H}+\mathrm{Al}$ & CTC & $\mathrm{V} \%$ \\
\hline & & $\mathrm{g} \mathrm{dm}^{-3}$ & \multicolumn{2}{|c|}{$--\mathrm{mg} \mathrm{dm}{ }^{-3}--$} & \multicolumn{4}{|c|}{ - } & $\%$ \\
\hline $0,0-0,1$ & 5,51 & 3,97 & 15,32 & 90,10 & 3,92 & 1,75 & 7,45 & 13,35 & 44,19 \\
\hline $0,1-0,2$ & 5,50 & 3,73 & 5,22 & 77,00 & 2,16 & 0,85 & 6,45 & 9,66 & 33,22 \\
\hline \multirow[t]{3}{*}{$0,2-0,3$} & 5,32 & 3,40 & 3,56 & 63,50 & 1,35 & 0,84 & 6,02 & 8,37 & 28,08 \\
\hline & \multicolumn{9}{|c|}{ Física $^{1}$} \\
\hline & $\begin{array}{c}\text { Argila } \\
----\end{array}$ & $\begin{array}{c}\text { Silte } \\
---\mathrm{g} \mathrm{kg}^{-1}\end{array}$ & Areia & $\begin{array}{c}\mathrm{DS}^{2} \\
\mathrm{~kg} \mathrm{dm}{ }^{-3}\end{array}$ & $\mathrm{PT}^{2}$ & $\begin{array}{r}N \\
---m \\
\end{array}$ & $\begin{array}{l}\mathrm{aP}^{2} \\
\mathrm{~m}^{-3}\end{array}$ & $\mathrm{MiP}^{2}$ & $\begin{array}{c}\mathrm{CH}^{2} \\
\mathrm{~mm} \mathrm{~h}^{-1}\end{array}$ \\
\hline $0,0-0,1$ & 530 & 163 & 307 & 1,17 & 0,52 & & 11 & 0,41 & 76,12 \\
\hline $0,1-0,2$ & 553 & 150 & 297 & 1,20 & 0,49 & &, 10 & 0,39 & - \\
\hline $0,2-0,3$ & 562 & 154 & 284 & - & - & & - & - & - \\
\hline
\end{tabular}

Densidade do solo (DS), porosidade total (PT), macroporosidade (MaP), microporosidade (MiC) e Condutividade hidráulica (CH). pH (água), M.O. (walking black), $\mathrm{P}$ e $\mathrm{K}$ (Mehlich), $\mathrm{Ca}$ e $\mathrm{Mg}(\mathrm{KCl})$ e $\mathrm{H}+\mathrm{Al}$ (Acetato de $\mathrm{Ca}$ ). ${ }^{1}$ Média de três amostras compostas, sendo que cada amostra composta foi proveniente de dez subamostras. ${ }^{(2)}$ média de dez amostras. 
cela era $6,6 \mathrm{~m}^{2}$, constituída das seis linhas centrais, avaliando-se os dois metros centrais destas.

A semeadura do milho foi realizada sobre os restos culturais da soja, e a cultivar utilizada foi a DKB 390 VT Pro 2, com aplicação de $80 \mathrm{~kg} \mathrm{ha}^{-1}$ de $\mathrm{N}$ no estádio V2 e $60 \mathrm{~kg} \mathrm{ha}^{-1}$ de $\mathrm{N}$ no estádio V5, a lanço em área total, ambas na forma de ureia. No dia 10 de julho de 2014, foram coletadas manualmente as espigas de $6,6 \mathrm{~m}^{2}$. Após a coleta das espigas, as plantas foram cortadas e acondicionadas na área correspondente a sua parcela, sendo o material fracionado em pedaços de aproximadamente $0,50 \mathrm{~m}$, simulando a colheita mecanizada.

No dia 25 de setembro de 2014, foi realizada a semeadura da soja sobre os restos culturais do milho, visando avaliar o efeito residual da adubação potássica e do aproveitamento do K presente na palhada do milho. A cultivar utilizada foi a TMG 132, adubada em pré-semeadura com $108 \mathrm{~kg} \mathrm{ha}^{-1}$ de $\mathrm{P}_{2} \mathrm{O}_{5}$ na forma de superfosfato simples aplicado a lanço. A colheita da cultura da soja ocorreu no dia 20 de janeiro de 2015, sendo colhidos $6,6 \mathrm{~m}^{2}$ dentro de cada parcela.

No dia 2 de fevereiro de 2015, sobre os restos culturais da soja, foi semeado o milho safrinha, utilizando o híbrido DKB 245 RR. Foram realizadas duas adubações nitrogenadas de cobertura a lanço: uma no estádio V2 e outra no V4, em ambas as adubações foram aplicados $50 \mathrm{~kg} \mathrm{ha}^{-1}$ de $\mathrm{N}$, em forma de ureia. A colheita foi realizada no dia 20 de junho de 2015 , sendo colhido $6,6 \mathrm{~m}^{2}$ por parcela.

$\mathrm{Na}$ cultura do milho, quando a planta se encontrava em maturação fisiológica, foram retiradas 10 espigas da área útil da parcela experimental e nestas foram realizadas a contagem de fileiras e grãos por fileiras. Em seguida, foram debulhadas, seus grãos levados a estufa $\left(105^{\circ} \mathrm{C}\right.$ por $\left.24 \mathrm{~h}\right)$ e realizada a obtenção da massa de 100 grãos de 3 amostras. Para determinar o rendimento de grãos, foram somados a produtividade em 12 metros lineares e os grãos das 10 espigas avaliadas anteriormente, com a umidade corrigida para $13 \%$.

Na cultura da soja, quando a planta se encontrava em maturidade fisiológica, foram coletadas 10 plantas da área útil de cada parcela para a contagem do número de vagens por planta e o número de grãos por vagem. A massa de 100 grãos e a produtividade foram obtidas da mesma maneira realizada na cultura do milho.

Na cultura do milho safra 2013/14 foram avaliadas as concentrações dos nutrientes $\mathrm{K}, \mathrm{Ca}, \mathrm{Mg}$ e $\mathrm{N}$, na folha, planta e nos grãos. Foram analisadas 10 folhas por parcelas, abaixo e oposta a espiga, quando a planta estava em pleno florescimento. No momento da colheita foram pesadas 10 plantas inteiras no campo, retirando-se a espiga (grãos e sabugo) e raízes, as quais foram subamostradas e levadas para estufa para retirar a umidade e posteriormente, calculada com base no estande a massa seca residual do milho por hectare. A análise dos grãos foi realizada com amostras durante o processo de colheita. Com os resultados das concentrações de nutrientes na planta e a sua massa seca somando o acumulado nos grãos, calculou-se a extração de nutrientes. A exportação de nutrientes foi determinada em função da produtividade de grãos e a concentração de nutrientes nos grãos. Para a safra de milho em 2014/15 foi analisada apenas a concentração de $\mathrm{K}$ nos grãos e a exportação deste.

$\mathrm{Na}$ cultura da soja foram realizadas as mesmas avaliações que na cultura do milho safra 2013/14. A folha foi coletada quando a planta se encontrava em pleno florescimento, coletando 10 folhas por parcela, sendo amostrada a terceira folha completamente desenvolvida do ápice para baixo. Para análise da planta inteira, exceto raízes, foram coletadas duas plantas 
por parcelas, quando se encontravam em estádio R7, após secas, pesadas e extrapolada a massa seca destas para hectare. Para análise de concentração de nutrientes nos grãos, foram obtidas as amostras no momento da colheita. Com os resultados das concentrações na planta e a sua massa seca, foi estimada a extração de nutrientes, e com a produtividade de grãos e a concentrações de nutrientes nos grãos, a exportação.

As análises de $\mathrm{N}$ nos tecidos vegetais foram efetuadas pelo método Kjeldahl (Silva, 2009), e a análise de N, Ca e Mg, segundo Malavolta et al. (1997).

Amostragens do solo para acompanhamento de atributos químicos foram realizadas após a colheita do milho safra 2013/14, aos 204 dias após a adubação, nas camadas de 0-0,1, 0,1-0,2 e 0,2-0,3 m, com auxílio de um trado tipo sonda. A amostra de cada parcela era composta por 15 subamostras. O solo coletado foi seco ao ar, passado na peneira de $2 \mathrm{~mm}$, e posteriormente foram analisados os seus atributos químicos (teor de $\mathrm{K}$, Ca e Mg), segundo metodologia descritas em Silva (2009).

Os resultados foram submetidos a análise de variância, e quando estes foram significativos, submetidos à análise de regressão, considerando-se o efeito das doses de potássio, com o nível de 5\% de probabilidade. Análises feitas no programa Sisvar (Ferreira, 2011).

\section{Resultados e Discussão}

As doses de cloreto de potássio $(\mathrm{KCl})$ afetaram apenas o teor de $\mathrm{K}$ no solo (Tabela 2), com comportamento linear em todas as camadas (Figura 2). A movimentação de K no perfil do solo é amplamente relatada pela literatura. O K é um elemento que se move no solo por difusão e se encontra na solução do solo quando em altas concentrações (Lange et al.,
2008; Werle et al., 2008). Esse movimento vertical é facilitado em condições de alta precipitação e/ou pelo excesso de irrigação (Albuquerque et al., 2011), podendo chegar ao ponto de ocorrer lixiviação do elemento para profundidades sem ocupação do sistema radicular da cultura. No presente trabalho, é possível observar que esta movimentação ocorre mesmo em solo com elevado teor de argila $\left(>530 \mathrm{~g} \mathrm{~kg}^{-1}\right)$ e sob baixa precipitação, com apenas $303 \mathrm{~mm}$ de chuva acumulados da adubação até a coleta de solo. Segundo Quaggio (2000), o pH pode ser um fator que influencia na percolação de potássio no solo, que pode ocorrer em condições de baixo valor de $\mathrm{pH}$, mesmo em solos argilosos.

O resumo da análise de variância demostrou efeito significativo para todos os atributos analisados no milho safrinha 2013/14, exceto para extração e exportação de Ca. Na soja (safra 2014/15) houve efeito significativo somente na concentração foliar de Ca e Mg. A exportação do milho safrinha 2014/15 não sofreu influência das fontes de variações (Tabela 3).

A concentração de $\mathrm{N}$ na folha ficou abaixo da faixa considerada ideal, independentemente da cultura (Sousa \& Lobato, 2004), com resposta linear apenas para as doses no milho safra 2013/14 (Figura 3A). As concentrações de $\mathrm{Ca}$ e $\mathrm{Mg}$ foram afetadas de forma linear, nas safras que foram avaliadas (milho safra 2013/14 e soja 2014/15), com redução na concentração foliar de acordo com o incremento das doses de K (Figura 3B e 3C). O mesmo comportamento foi observado por Santos et al. (2015) na cultura do sorgo, em que doses de $\mathrm{K}$ proporcionaram uma menor concentração foliar de $\mathrm{Ca}$ e $\mathrm{Mg}$. Mesmo com a diminuição da concentração de $\mathrm{Ca}$ e $\mathrm{Mg}$ nas doses mais elevadas, estas ficaram dentro da faixa ideal (Sousa \& Lobato, 2004). Este comportamento pode ser explicado pela interação entre nutrientes no solo, 
Tabela 2. Análise estatística para os teores dos nutrientes: potássio, cálcio e magnésio no solo, nas camadas 0-0,1, 0,1-0,2 e 0,2-0,3 m em função de doses de potássio. Coleta de solo realizada 204 dias após a adubação. Sorriso-MT.

\begin{tabular}{|c|c|c|c|c|c|c|c|c|c|}
\hline \multirow{3}{*}{ Doses de K } & \multicolumn{9}{|c|}{ Camadas (m) } \\
\hline & \multicolumn{3}{|c|}{$0,0-0,1$} & \multicolumn{3}{|c|}{$0,1-0,2$} & \multicolumn{3}{|c|}{$0,2-0,3$} \\
\hline & $\mathrm{K}$ & $\mathrm{Ca}$ & $\mathrm{Mg}$ & $\mathrm{K}$ & $\mathrm{Ca}$ & $\mathrm{Mg}$ & $\mathrm{K}$ & $\mathrm{Ca}$ & $\mathrm{Mg}$ \\
\hline $\mathrm{kg} \mathrm{ha}^{-1}$ & $\mathrm{mg} \mathrm{dm}^{-3}$ & \multicolumn{2}{|c|}{$---\mathrm{cmol}_{\mathrm{c}} \mathrm{dm}^{-3}----$} & $\mathrm{mg} \mathrm{dm}{ }^{-3}$ & \multicolumn{2}{|c|}{---- $\mathrm{cmol}_{\mathrm{c}} \mathrm{dm}^{-3}$} & $\mathrm{mg} \mathrm{dm} \mathrm{dm}^{-3}$ & \multicolumn{2}{|c|}{$---\mathrm{cmol}_{\mathrm{c}} \mathrm{dm}^{-3}--$} \\
\hline 0 & 87,7 & 3,4 & 2,3 & 66,0 & 2,2 & 1,7 & 60,0 & 1,6 & 1,8 \\
\hline 40 & 85,8 & 3,5 & 2,2 & 66,7 & 2,3 & 1,7 & 56,8 & 1,6 & 1,7 \\
\hline 80 & 104,3 & 3,2 & 2,0 & 75,3 & 2,0 & 1,7 & 67,0 & 1,7 & 1,6 \\
\hline 120 & 111,3 & 3,4 & 1,9 & 84,3 & 2,2 & 1,7 & 77,3 & 1,7 & 2,2 \\
\hline $\mathrm{p}$ & 0,039 & 0,346 & 0,278 & 0,034 & 0,210 & 0,945 & 0,002 & 0,478 & $0,012 *$ \\
\hline CV (\%) & 16,68 & 9,85 & 18,01 & 14,88 & 10,51 & 12,56 & 12,29 & 8,12 & 8,68 \\
\hline Média & 97,29 & 3,38 & 2,08 & 73,08 & 2,17 & 1,70 & 65,29 & 1,63 & 1,74 \\
\hline
\end{tabular}

* significativo a $5 \%$ de probabilidade pelo teste $\mathrm{F}(\mathrm{p}<0,05)$, porém sem ajuste de regressão.

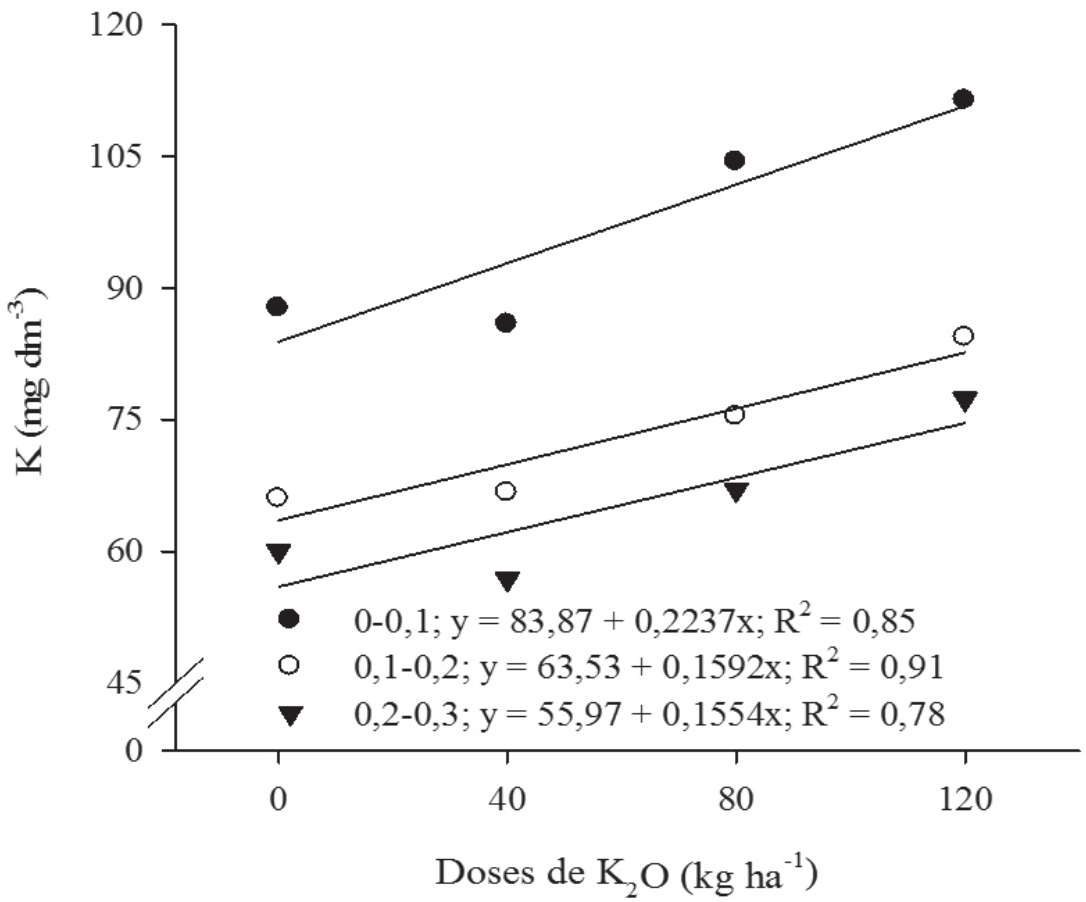

Figura 2. Teores de potássio no solo nas camadas 0-0,1, 0,1-0,2 e 0,2-0,3m em função de doses de potássio, coleta realizada 204 dias após a adubação, em Sorriso-MT.

onde um nutriente prejudica ou favorece a absorção de outro (Raij, 2011).

A concentração de $\mathrm{K}$ foliar no milho, safra 2013/14, foi máxima na dose de $71 \mathrm{~kg} \mathrm{ha}^{-1}$ (Figura $3 \mathrm{~A})$. As concentrações em todas as doses são consideradas adequadas para a cultura, variando de 13 a 30 $\mathrm{g} \mathrm{kg}^{-1}$ (Sousa \& Lobato, 2004). Os autores Petter et al. (2016) e Valderrama et al. (2011) também observaram aumento na concentração de $\mathrm{K}$ foliar em milho submetido a doses de $\mathrm{K}$, ambos com aumento linear, com a maior dose testada sendo a mesma do presente estudo. A concentração de $\mathrm{K}$ foliar na cultura da soja 
Tabela 3. Resumo da análise estatística para as variáveis; concentração foliar (FOL.), extração de nutrientes (EXT.) e exportação de nutrientes (EXP.) para os nutrientes; potássio, cálcio, magnésio e nitrogênio. Sorriso -MT, safras 2013/14 e 2014/15 em função de doses de potássio.

\begin{tabular}{|c|c|c|c|c|c|c|c|}
\hline \multirow[b]{2}{*}{$\begin{array}{l}\text { Doses } \\
\mathrm{kg} \mathrm{ha}^{-1}\end{array}$} & \multicolumn{3}{|c|}{ Milho 2013/14 } & \multicolumn{3}{|c|}{ Soja 2014/15 } & \multirow{2}{*}{$\begin{array}{c}\text { Milho 2014/15 } \\
\text { EXP. } \\
\mathrm{kg} \mathrm{ha}^{-1}\end{array}$} \\
\hline & $\begin{array}{l}\text { FOL. } \\
\mathrm{g} \mathrm{kg}^{-1}\end{array}$ & $\begin{array}{c}\text { EXT. } \\
\mathrm{kg} \mathrm{ha}^{-1}\end{array}$ & $\begin{array}{c}\text { EXP. } \\
\mathrm{kg} \mathrm{ha}^{-1}\end{array}$ & $\begin{array}{l}\text { FOL. } \\
\mathrm{g} \mathrm{kg}^{-1}\end{array}$ & $\begin{array}{c}\text { EXT. } \\
\mathrm{kg} \mathrm{ha}^{-1}\end{array}$ & $\begin{array}{c}\text { EXP. } \\
\mathrm{kg} \mathrm{ha}^{-1}\end{array}$ & \\
\hline & \multicolumn{7}{|c|}{ Potássio } \\
\hline 0 & 33,81 & 260,88 & 10,48 & 21,42 & 138,87 & 52,70 & 34,05 \\
\hline 40 & 34,21 & 295,80 & 15,15 & 22,33 & 166,76 & 54,81 & 33,55 \\
\hline 80 & 35,82 & 298,79 & 17,48 & 22,51 & 167,35 & 54,35 & 33,66 \\
\hline 120 & 34,39 & 300,89 & 15,95 & 22,26 & 160,13 & 52,28 & 33,29 \\
\hline $\mathrm{p}$ & 0,005 & 0,012 & 0,012 & 0,161 & 0,126 & 0,641 & 0,916 \\
\hline $\mathrm{CV}(\%)$ & 2,43 & 7,05 & 22,04 & 3,83 & 13,82 & 7,45 & 7,51 \\
\hline \multirow[t]{2}{*}{ Média } & 34,56 & 289,09 & 14,77 & 22,13 & 158,28 & 53,54 & 33,64 \\
\hline & \multicolumn{7}{|c|}{ Cálcio } \\
\hline 0 & 4,13 & 59,40 & 6,27 & 10,20 & 71,33 & 11,62 & - \\
\hline 40 & 4,01 & 61,16 & 6,55 & 9,42 & 77,49 & 11,51 & - \\
\hline 80 & 3,77 & 64,37 & 6,85 & 9,96 & 81,47 & 11,61 & - \\
\hline 120 & 3,80 & 64,67 & 7,00 & 9,47 & 83,66 & 12,04 & - \\
\hline $\mathrm{p}$ & 0,023 & 0,404 & 0,324 & 0,004 & 0,159 & 0,382 & - \\
\hline $\mathrm{CV}(\%)$ & 5,22 & 9,82 & 10,67 & 3,69 & 11,97 & 4,73 & - \\
\hline \multirow[t]{2}{*}{ Média } & 3,93 & 62,40 & 6,67 & 9,76 & 78,48 & 11,70 & - \\
\hline & \multicolumn{7}{|c|}{ Magnésio } \\
\hline 0 & 2,07 & 41,13 & 11,83 & 5,33 & 28,28 & 7,48 & - \\
\hline 40 & 2,05 & 45,68 & 13,43 & 5,19 & 32,76 & 7,65 & - \\
\hline 80 & 1,79 & 47,95 & 14,97 & 5,18 & 31,59 & 7,63 & - \\
\hline 120 & 1,57 & 44,05 & 15,27 & 5,17 & 32,43 & 8,01 & - \\
\hline $\mathrm{p}$ & 0,000 & 0,112 & 0,035 & 0,033 & 0,299 & 0,160 & - \\
\hline $\mathrm{CV}(\%)$ & 8,29 & 10,23 & 10,49 & 1,83 & 13,9 & 5,04 & - \\
\hline \multirow[t]{2}{*}{ Média } & 1,87 & 44,70 & 13,87 & 5,22 & 31,26 & 7,69 & - \\
\hline & \multicolumn{7}{|c|}{ Nitrogênio } \\
\hline 0 & 25,20 & 159,93 & 95,70 & 35,88 & 238,35 & 164,72 & - \\
\hline 40 & 25,44 & 176,89 & 105,93 & 36,78 & 266,21 & 166,60 & - \\
\hline 80 & 26,49 & 182,59 & 110,58 & 34,81 & 269,65 & 164,65 & - \\
\hline 120 & 26,90 & 172,89 & 110,62 & 36,54 & 267,74 & 170,98 & - \\
\hline $\mathrm{p}$ & 0,007 & 0,004 & 0,045 & 0,226 & 0,128 & 0,509 & - \\
\hline $\mathrm{CV}(\%)$ & 3,14 & 5,17 & 8,80 & 4,70 & 9,35 & 4,86 & - \\
\hline Média & 26,01 & 173,07 & 105,71 & 36,00 & 260,49 & 166,74 & - \\
\hline
\end{tabular}

encontra-se na faixa considera adequada por Sousa e Lobato (2004), entre 17 e $25 \mathrm{~g} \mathrm{~kg}^{-1}$.

Somente as extrações dos nutrientes $\mathrm{K}$ e $\mathrm{N}$, no milho 2013/14, tiveram influência das doses de
K com extração de K demonstrando comportamento linear e do $\mathrm{N}$ quadrático. A máxima extração de $\mathrm{K}$ foi alcançada na dose de $72 \mathrm{~kg} \mathrm{ha}^{-1}$ de $\mathrm{K}_{2} \mathrm{O}$ (Figura 3D). Isto relaciona-se ao aumento da massa seca to- 

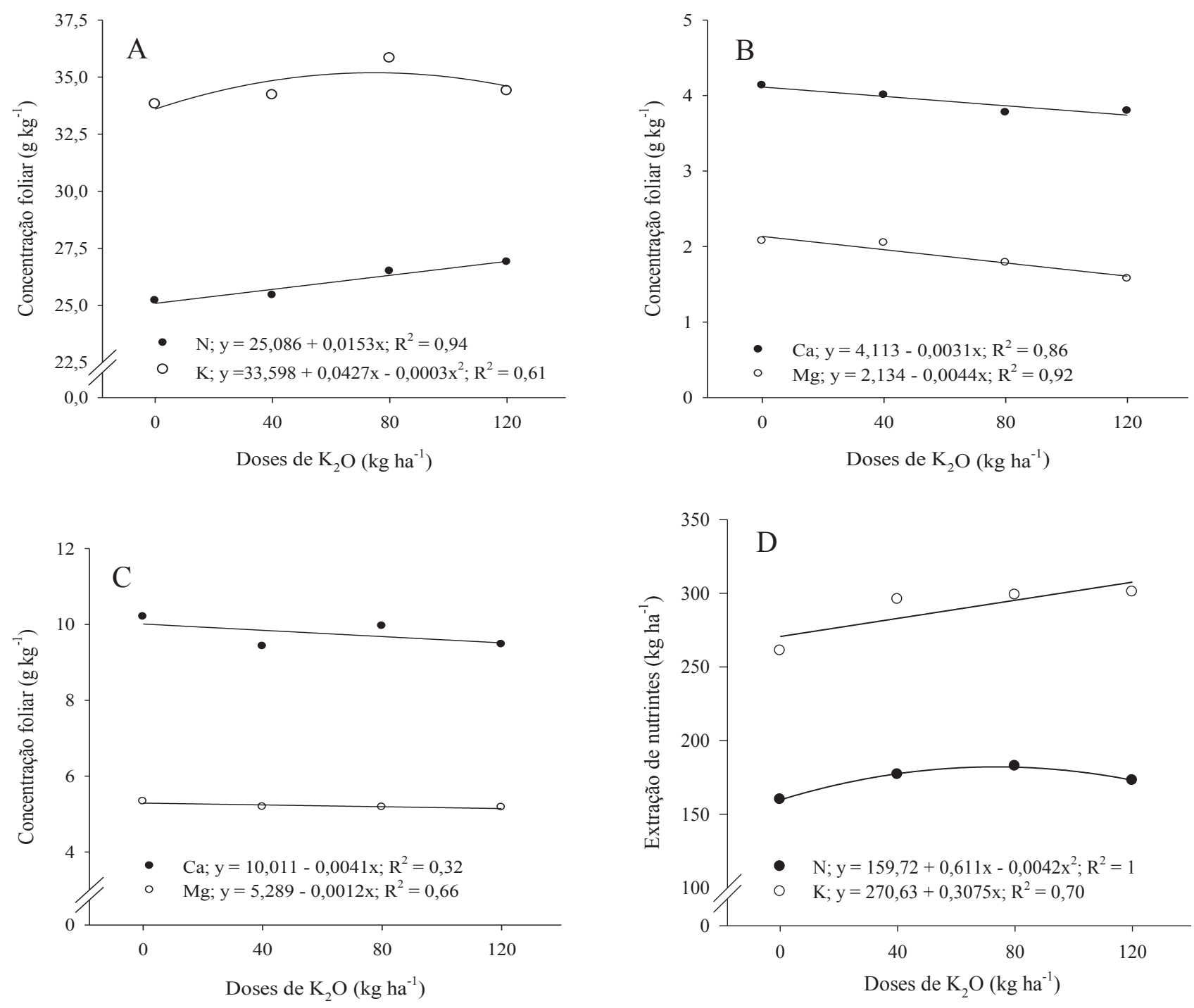

Figura 3. Concentração foliar de nitrogênio e potássio no milho safra 2013/14 (A), cálcio e magnésio no milho safra 2013/14 (B), cálcio e magnésio na soja safra 2014/15 (C) e extração de nitrogênio e potássio pelo milho safra 2013/14 (D) em função de doses de potássio, em Sorriso-MT.

tal (restos culturais + grãos) do milho safra 2013/14 perante o aumento das doses, mesmo esta não sendo significativa. Somado à maior produção de biomassa seca com maior concentração de $\mathrm{K}$ e $\mathrm{N}$ nesta, promoveu aumento na extração destes nutrientes. Em contrapartida, o Ca e $\mathrm{Mg}$ tiveram a sua concentração afetada negativamente pelas doses, anulando o efeito da maior produção de biomassa seca, mantendo a taxa de extração praticamente a mesma, independentemente da dose de K utilizada.

A exportação de nutrientes foi influenciada pelas doses somente no milho safra 2013/14, e o efeito residual da adubação potássica não influenciou as exportações nas safras seguintes (Tabela 3). O K e o N apresentaram uma distribuição quadrática perante o aumento das doses, sendo observada a máxima ex- 
portação nas doses de 82 e $98 \mathrm{~kg} \mathrm{ha}^{-1}$ de $\mathrm{K}_{2} \mathrm{O}$, respectivamente. $\mathrm{O} \mathrm{Mg}$ apresentou uma distribuição linear exportando $\sim 15 \mathrm{~kg} \mathrm{ha}^{-1} \mathrm{de} \mathrm{Mg}$, na dose de $120 \mathrm{~kg} \mathrm{ha}^{-1}$ de $\mathrm{K}_{2} \mathrm{O}$ (Figura 4A e 4B).

No presente trabalho foram observadas uma maior extração e uma menor exportação de K, comparados aos dados apresentados por Coelho (2006), provavelmente vinculadas a maior produção de restos culturais e menor produtividade obtida no presente estudo (milho safra 2013/14). Respostas contrastantes também foram observadas para os nutrientes $\mathrm{Ne} \mathrm{Ca}$, contudo o $\mathrm{Mg}$ corroborou com os dados do referido autor.

A massa de cem grãos e produtividade no milho, safra 2013/14, a massa de cem grãos da soja safra 2014/15 e rendimento de grãos acumulado no decorrer dos três cultivos apresentaram diferença significativa para o uso de doses de $\mathrm{K}_{2} \mathrm{O}$ no milho safrinha 2013/14 (Tabela 4). A massa de grãos na soja apresentou diferença pelo teste $\mathrm{F}$, mas não houve ajuste de curva. A diferença foi possível por causa do baixo coeficiente de variação (1,51\%), com as médias sendo praticamente iguais, 11,$0 ; 11,3 ; 11,0$ e 11,1 gramas por 100 grãos, respectivamente, para as doses 0,40 , 80 e $120 \mathrm{~kg} \mathrm{ha}^{-1}$ de $\mathrm{K}_{2} \mathrm{O}$.

A baixa resposta à adubação potássica no sistema pode ser atribuída ao teor inicial de $\mathrm{K}$ no solo (Tabela 1), valor acima dos teores considerados limitantes, que segundo Petter et al. (2012) é de $70 \mathrm{mg}$ $\mathrm{dm}^{-3}$. Em literatura mais antiga este valor é de $53 \mathrm{mg}$ $\mathrm{dm}^{-3}$ (Sousa \& Lobato, 2004), assim as culturas possivelmente usaram as reservas de $\mathrm{K}$ do solo para suprir suas necessidades fisiológicas ou as reservas dos resíduos culturais.

A produtividade de grãos do milho safra 2013/14 apresentou resposta linear em função das doses de $\mathrm{K}$ (Figura $5 \mathrm{~A}$ ), com aumento de $1.111 \mathrm{~kg} \mathrm{ha}^{-1}$ (adubação com $120 \mathrm{~kg} \mathrm{ha}^{-1}$ de $\mathrm{K}_{2} \mathrm{O}$ ) em comparação a testemunha. Petter et al. (2016) também obtiveram resposta na cultura do milho em função de doses de $\mathrm{K}$ na adubação, porém a produtividade máxima foi obtida na dose de $53 \mathrm{~kg} \mathrm{ha}^{-1}$ de $\mathrm{K}_{2} \mathrm{O}$, mesmo o teor no solo sendo inferior ao do presente estudo.

A maior produtividade foi reflexo da maior massa de grãos (Figura 5B), sendo que o número de

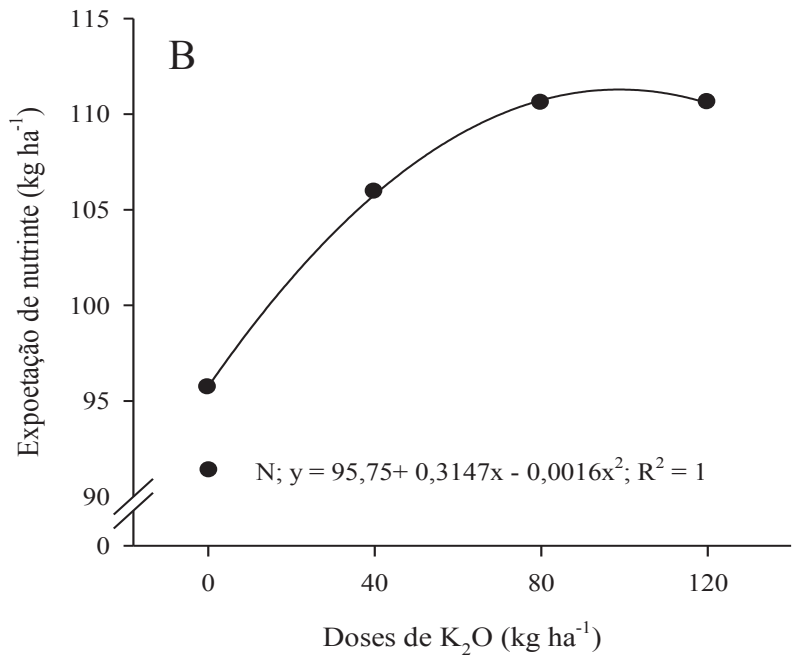

Figura 4. Exportação dos nutrientes magnésio e potássio (A), nitrogênio (B) pelo milho safrinha 2013/14 em função de doses de potássio, em Sorriso-MT. 
Tabela 4. Resumo da análise estatística para as variáveis; massa de 100 grãos (M100), número de grãos por fileira (NGF), número de fileiras por espiga (NF), produtividade (PRO), número de grãos por vagem (NGV) e número de vagens por planta (NV). Sorriso-MT, safras 2013/14 e 2014/15 em função de doses de potássio.

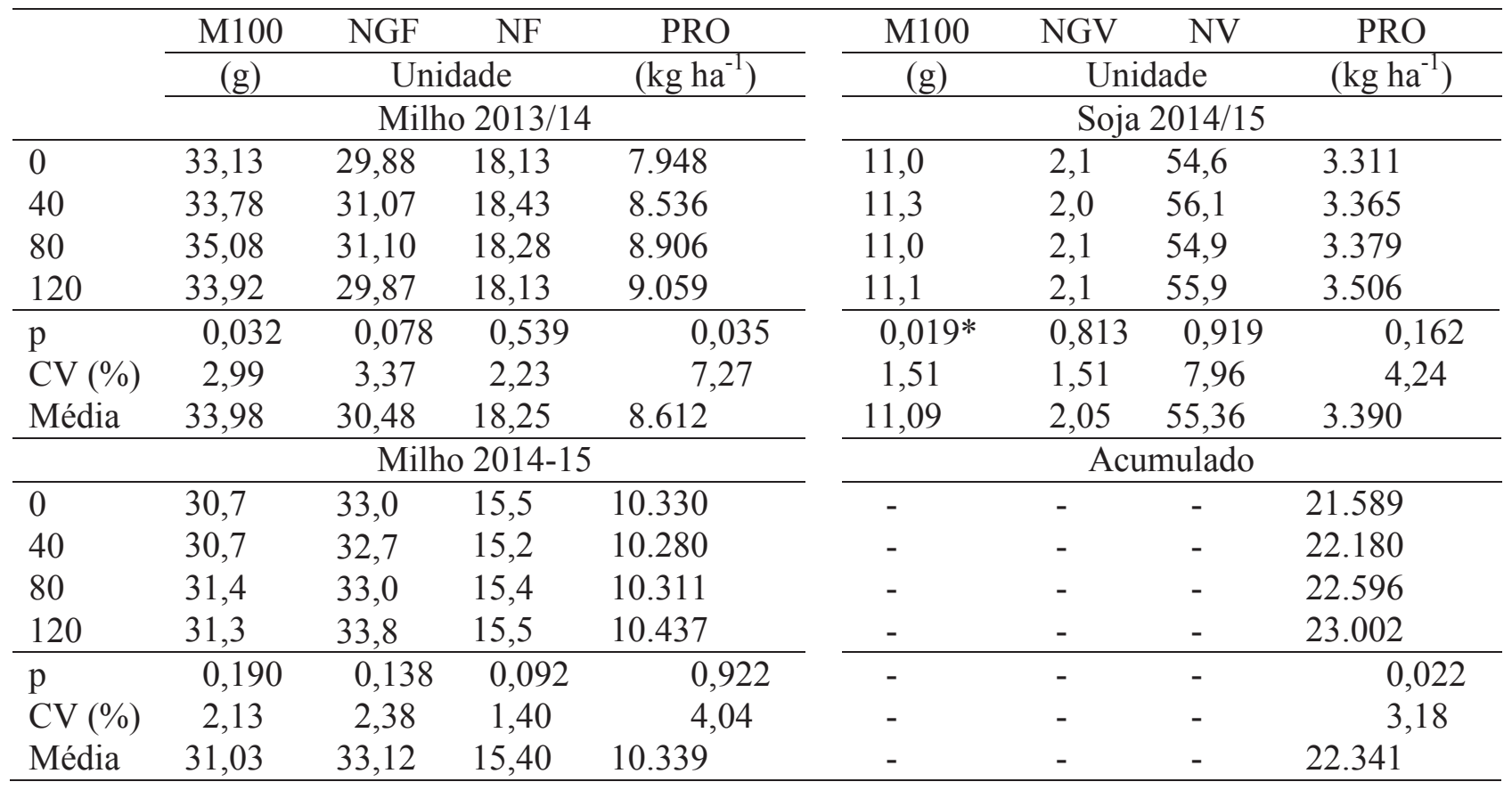

* significativo a $5 \%$ de probabilidade pelo teste $\mathrm{F}(\mathrm{p}<0,05)$, porém sem ajuste de regressão.
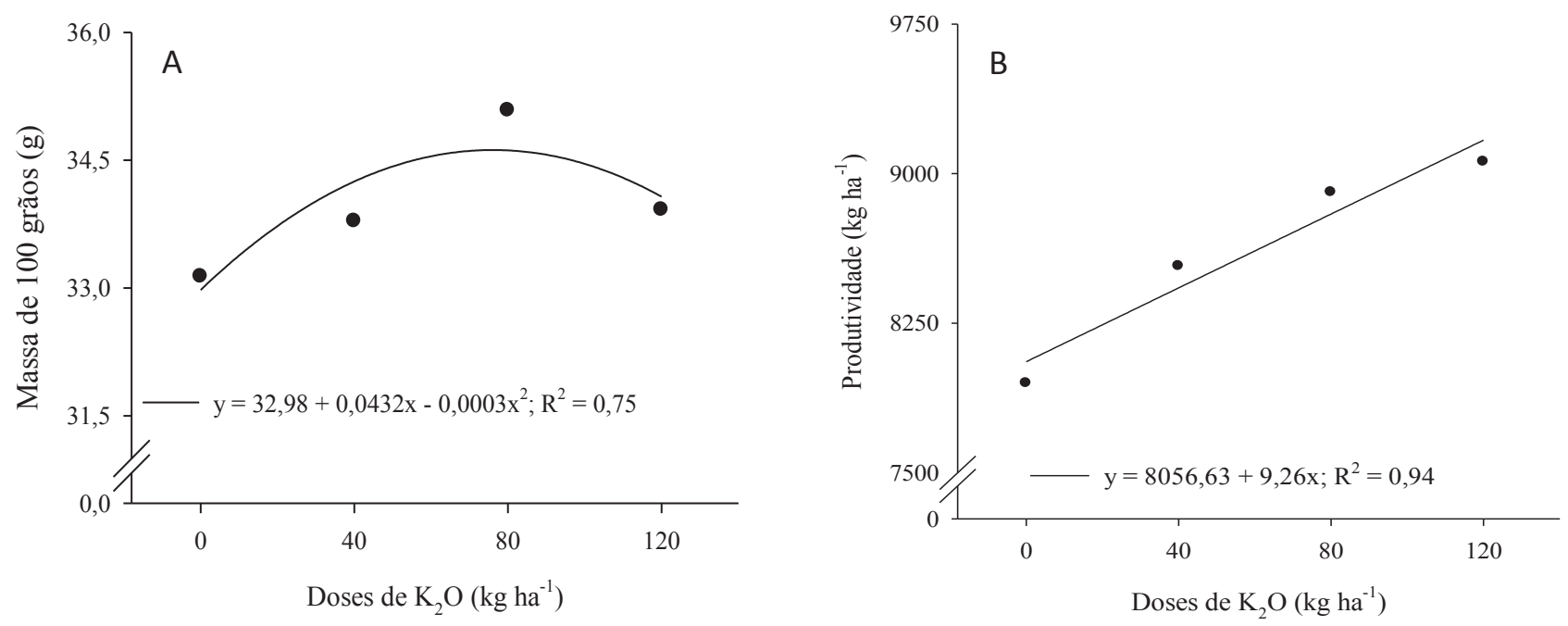

Figura 5. Massa de 100 grãos (A) e produtividade (B) do milho safrinha 2013/14 em função de doses de potássio, em Sorriso-MT. 
grãos e de fileiras por espigas não foi alterado, contrastando com o encontrado por Petter et al. (2016) e Valderrama et al. (2011). Os autores citam que as doses de $\mathrm{K}$ aumentaram o número de fileiras por espigas e consequentemente o número de grãos, resultando em grãos de menor massa.

Entre os fatores que favoreceram a resposta das doses de K no milho safra 2013/14 e não o fizeram na safra 2014/15, destacam-se as condições climáticas favoráveis e a época de semeadura para o $2^{\circ}$ ano do estudo. Estas condições proporcionaram uma menor produtividade do milho na safra 2013/14 comparada com a safra 2014/15 (média $1.740 \mathrm{~kg}$ a menos por hectare), em razão da semeadura tardia, no início de março, sendo que a janela ideal, levando em consideração as características do solo e da cultivar, era até 31 de janeiro (Brasil, 2017).

Somado a isto, após a semeadura do milho safrinha (2013/14), houve precipitação atípica para região do estudo, onde se registrou o acumulado de apenas $227 \mathrm{~mm}$, sendo que a última chuva expressiva ocorreu 29 dias após a semeadura, o que reduziu significativamente o potencial produtivo da cultura. Já na safrinha do milho no ano seguinte (2014/15), a semeadura foi realizada no início de fevereiro e se obteve acúmulo de $1.053 \mathrm{~mm}$, com ocorrência de chuvas até os 98 dias após a semeadura.

A disponibilidade de água no solo é importante para a absorção de $\mathrm{K}$ pelas plantas, mas, mesmo em condições de menor disponibilidade hídrica no milho safra 2013/14, a alta concentração de K no solo foi capaz de proporcionar absorção suficiente para atender a demanda do nutriente pela planta, enquanto em condições ideais de umidade no solo na safra seguinte, mesmo com as concentrações de $\mathrm{K}$ no solo reduzidas por causa da extração e exportação do nutriente pelas safras anteriores, foi possível atender a demanda pela cultura.
É importante ressaltar que a pluviosidade apresentada durante a safrinha 2013/14 é anormal para a região. Registros da mesma estação meteorológica mostram que a média dos 5 anos anteriores, ao início do estudo, foi de $612 \mathrm{~mm}$. Cabe ressaltar que o plantio e a adubação foram realizados fora da janela apropriada para a cultura e região, por causa do atraso na semeadura da soja ocasionado pelo atraso do período de chuvas.

Dessa forma, se a semeadura do milho safrinha (2013/14) fosse realizada na época adequada teria maior precipitação acumulada, consequentemente, a lixiviação, extração e exportação de nutrientes alteraria os resultados apresentados. A dinâmica do $\mathrm{K}$ é variável no sistema de produção conforme os cultivos realizados, demostrando a importância de maior controle na aplicação da adubação potássica e a necessidade de mais estudos sobre o assunto na região Médio Norte do Mato Grosso.

A cultura da soja normalmente é menos responsiva à adubação potássica, pois tem baixa exigência sobre o K. No estudo em questão, o teor de K no solo até a $30 \mathrm{~cm}$ era superior a $65 \mathrm{mg} \mathrm{dm}^{-3}$, com o acúmulo na palhada de milho superior a $250 \mathrm{~kg} \mathrm{ha}^{-1}$ de $\mathrm{K}$, o que sustentaria suficientemente a produtividade alcançada. Segundo Scherer (1998), respostas da cultura da soja à adubação potássica são muito baixas ou inexistentes quando o teor no solo estiver maior que $60 \mathrm{mg} \mathrm{dm}^{-3}$, no entanto Petter et al. (2012) observaram resposta da soja em solo com teor de $\mathrm{K}$ de $77 \mathrm{mg} \mathrm{dm}{ }^{-3}$, com incremento na produtividade até a dose de $97 \mathrm{~kg} \mathrm{ha}^{-1}$ de $\mathrm{K}_{2} \mathrm{O}$.

A produtividade acumulada nos três cultivos respondeu de forma linear às doses de $\mathrm{K}$ (Figura 6), havendo um incremento de $1.412 \mathrm{~kg} \mathrm{ha}^{-1}$ comparando a testemunha com a dose de $120 \mathrm{~kg} \mathrm{ha}^{-1}$ de $\mathrm{K}_{2} \mathrm{O}$, sendo $1.111 \mathrm{~kg} \mathrm{ha}^{-1}$ provenientes do milho safrinha (2013/14), $194 \mathrm{~kg} \mathrm{ha}^{-1}$ da soja safra (2014/15) e 107 $\mathrm{kg}$ do milho safrinha (2014/15). 


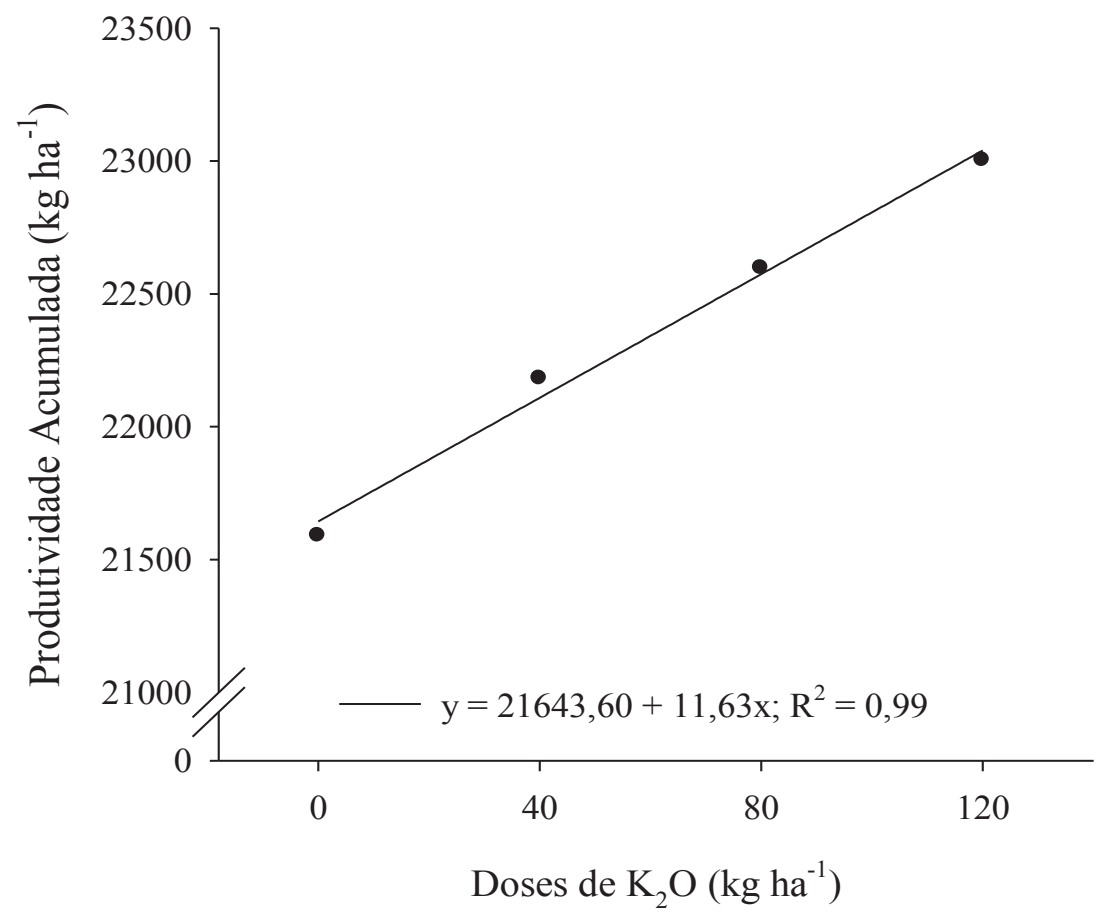

Figura 6. Produtividade acumulada (milho safrinha + soja safra + milho safrinha) safras 2013/14 e 2014/15, em função de doses de potássio, em Sorriso-MT.

\section{Conclusões}

A soja em solo com teor adequado de K é pouca responsiva à adubação potássica, no sistema soja-milho safrinha, porque as reservas no solo e nos restos culturais do milho safrinha suprem suas necessidades.

Doses de K afetam a concentração de N, K, Ca e $\mathrm{Mg}$ nos tecidos foliares de milho e de $\mathrm{Mg}$ na soja, no sistema soja-milho safrinha.

A dose de $\mathrm{K}$ na adubação interfere na taxa de extração e exportação de nutrientes no milho safrinha.

O K apresenta movimentação no perfil, mesmo em solo argiloso sob baixa precipitação.

\section{Agradecimento}

Ao Eng. Agr. MSc Ivan Bedin, pela cessão da área experimental e apoio na execução do experimento, a José Antônio Costa, da Fundação Mato Grosso pela disponibilização dos dados climáticos, à fundação AGRISUS, pelo apoiofinanceiro para execução do projeto, e à Fundação de Amparo à Pesquisa (FAPEMAT), pela concessão de bolsa de estudo do segundo autor.

\section{Referências}

ALBUQUERQUE, F. S.; SILVA, E. F. F.; SOUZA, A. E. R.; ROLIM, M. M. Lixiviação de potássio em um cultivo 
de pimentão sob lâminas de irrigação e doses de potássio. Revista Caatinga, Mossoró, v. 24, n. 3, p. 135-144, 2011.

ALVAREZ V., V. H.; NOVAIS, R. F.; BARROS, N. F.; CANTARUTTI, R. B.; LOPES, A. S. Interpretação dos resultados das análises de solos. In: RIBEIRO, A. C.; GUIMARÃES, P. T. G.; ALVAREZ V., V. H. (Ed.). Recomendação para uso de corretivos e fertilizantes em Minas Gerais: $5^{\text {a }}$ aproximação. Viçosa, MG: Comissão de Fertilidade do Solo do Estado de Minas Gerais, 1999. p. 25-32.

BRASIL. Ministério da Agricultura, Pecuária e Abastecimento. Zoneamento agrícola: Mato Grosso: milho. Brasília, DF, 2017. Disponível em: <http:// www.agricultura.gov.br/assuntos/riscos-seguro/riscoagropecuario/portarias/safra-vigente/mato-grosso>. Acesso em: 8 ago. 2017.

COELHO, A. M. Nutrição e adubação do milho. Sete Lagoas: Embrapa Milho e Sorgo, 2006. 10 p. (Embrapa Milho e Sorgo. Circular Técnica, 78).

COELHO, A. M.; FRANCA, G. E. de; PITTA, G. V. E.; ALVES, V. M. C.; HERNANI, L. C. Fertilidade de solos: nutrição e adubação do milho. In: CRUZ, J. C. (Ed.). Cultivo do milho. 3. ed. Sete Lagoas: Embrapa Milho e Sorgo, 2007. (Embrapa Milho e Sorgo. Sistemas de Produção, 1).

CONAB. Séries históricas das safras. Brasília, DF, 2016. Disponível em: <http://www.conab.gov.br/ conteudos.php? $\mathrm{a}=1252 \&$ Pagina_objcmsconteudos $=3 \# \mathrm{~A}$ objcmsconteudos>. Acesso em: 9 ago. 2017.

FERREIRA, D. F. Sisvar: a computer statistical analysis system. Ciência e Agrotecnologia, Lavras, v. 35, n. 6, p. 1039-1042, 2011.

DOI: 10.1590/S1413-70542011000600001.

LANGE, A.; CRUZ, J. C.; MARQUES, J. J. Estoque de nutrientes no perfil do solo influenciados por doses de palha e nitrogênio no milho em semeadura direta. Revista de Ciências Agro-Ambientais, Alta Floresta, v. 6, n. 1, p. 29-38, 2008.
MALAVOLTA, E.; VITTI G. C.; OLIVEIRA S. A. Avaliação do estado nutricional das plantas. 2. ed. Piracicaba: Associação Brasileira para Pesquisa da Potássio e do Fosfato, 1997. 319 p.

PETTER, F. A.; ANDRADE, F. R.; ZUFFO, A. M.; MONTEIRO, M. M. S.; PACHECO, L. P.; ALMEIDA, F. A. Doses e épocas de aplicação de potássio no desempenho agronômico do milho no cerrado piauiense. Comunicata Scientiae, v. 7, n. 3, p. 372-382, 2016.

DOI: $10.14295 / C S . v 7 i 3.1218$.

PETTER, F. A.; SILVA, J. A.; PACHECO, L. P.; ALMEIDA, F. A.; ALCÂNTARA NETO, F.; ZUFFO, A. M.; LIMA, L. B. Desempenho agronômico da soja a doses e épocas de aplicação de potássio no cerrado piauiense. Revista de Ciências Agrárias, v. 55, n. 3, p. 190-196, 2012. DOI: 10.4322/rca.2012.057.

QUAGGIO, J. A. Acidez e calagem em solos tropicais. Campinas: Instituto Agronômico de Campinas, 2000.

RAIJ, B. Van. Fertilidade do solo e manejo de nutrientes. Piracicaba: International Plant Nutrition Institute, 2011. $420 \mathrm{p}$.

SANTOS, F. C.; ALBUQUERQUE FILHO, M. R.; RESENDE, A. V.; OLIVEIRA, A. C.; OLIVEIRA, M. S.; GOMES, T. C. Adubação nitrogenada e potássica na nutrição e na extração de macronutrientes pelo sorgo biomassa. Revista Brasileira de Milho e Sorgo, Sete Lagoas, v. 14, n. 1, p. 10-22, 2015.

DOI: 10.18512/1980-6477/rbms.v14n1p10-22.

SCHERER, E. E. Resposta da soja à adubação potássica em Latossolo húmico distrófico num período de doze anos. Revista Brasileira de Ciência do Solo, Viçosa, MG, v. 22, n. 1, p. 49-55, 1998. DOI: $10.1590 / \mathrm{S} 0100-06831998000100007$.

SILVA, F. C. da (Ed.). Manual de análises químicas de solos, plantas e fertilizantes. 2. ed. Brasília, DF: Embrapa Informação Tecnológica; Rio de Janeiro: Embrapa Solos, 2009. $627 \mathrm{p}$ 
SOUSA, D. M. G.; LOBATO, E. Cerrado: correção do solo e adubação. 2. ed. Brasília, DF: Embrapa Informação Tecnológica; Planaltina, DF: Embrapa Cerrados, 2004. $416 \mathrm{p}$.

TAKASU, A. T.; HAGA, K. I.; RODRIGUES, R. A. F.; ALVES, C. J. Produtividade da cultura do milho em resposta à adubação potássica. Revista Brasileira de Milho e Sorgo, Sete Lagoas, v. 13, n. 2, p. 154-161, 2014. DOI: 10.18512/1980-6477/rbms.v13n2p154-161.

VALDERRAMA, M.; BUZETTI, S.; BENETT, C. G. S.; ANDREOTTI, M.; TEIXEIRA FILHO, M. C. M. Fontes e doses de NPK em milho irrigado sob plantio direto.
Pesquisa Agropecuária Tropical, Goiânia, v. 41, n. 2, p. 254-263, 2011. DOI: 10.5216/pat.v41i2.8390.

VILELA, L.; SOUSA, D. M. G.; SILVA, J. E. Adubação potássica. In: SOUSA, D. M. G.; LOBATO, E. Cerrado: correção do solo e adubação. 2. ed. Brasília, DF: Embrapa Informação Tecnológica; Planaltina, DF: Embrapa Cerrados, 2004. p. 169-184.

WERLE, R.; GARCIA, R.A.; ROSOLEM, C. A. Lixiviação de potássio em função da textura e da disponibilidade do nutriente no solo. Revista Brasileira de Ciência do Solo, Viçosa, MG, v. 32, n. 6, p. 2297-2305, 2008.

DOI: $10.1590 / \mathrm{S} 0100-06832008000600009$. 